\title{
Integrated assessment of international climate mitigation commitments outside the UNFCCC
}

\author{
Mark Roelfsema $^{\mathrm{a}, *}$, Mathijs Harmsen ${ }^{\mathrm{a}}$, Jos J.G. Olivier ${ }^{\mathrm{a}}$, Andries F. Hof ${ }^{\mathrm{a}, \mathrm{b}}$, Detlef P. van Vuuren ${ }^{\mathrm{a}, \mathrm{b}}$ \\ a PBL Netherlands Environmental Assessment Agency, P.O. Box 303, 3720 AH Bilthoven, The Netherlands \\ ${ }^{\mathrm{b}}$ Utrecht University, Copernicus Institute of Sustainable Development, Utrecht, The Netherlands
}

\section{A R T I C L E I N F O}

\section{Keywords:}

International cooperative initiatives

Non-state actors

Cities

Companies

Climate policy

NDCs

\begin{abstract}
A B S T R A C T
In the Paris Agreement under the United Nations Framework Convention on Climate Change (UNFCCC), for the first time, non-state actors were addressed in the international negotiations and were explicitly invited to act on climate change. Indeed, there are many transnational emission reduction initiatives (TERIs) outside the UNFCCC, driven by non-state actors or national governments, which aim at reducing greenhouse gas (GHG) emissions. Using an Integrated Assessment Model (IAM), this study assessed the potential impact of a selection of large TERIs that existed before the Paris Agreement on global greenhouse gas emissions. TERIs could lead to significant emission reductions: the eleven selected initiatives included in the analysis here could - if fully implemented - deliver annual GHG emission reductions of $2.5 \mathrm{GtCO}_{2}$ eq by 2020 and of $5.0 \mathrm{GtCO}_{2} \mathrm{eq}$ by 2030 from a no-policy-baseline emission level of $53.7 \mathrm{GtCO}_{2}$ and $61.1 \mathrm{GtCO}_{2} \mathrm{eq}$, respectively. Although these reductions are of similar magnitude as those pledged by countries under the umbrella of the UNFCCC, these reductions may significantly overlap with those of pledges and Nationally Determined Contributions. The maximum estimate of overlap is around $70 \%$ by 2020 and $80 \%$ by 2030 . This means that the combined impact on global GHG emissions of TERIs and NDCs, assuming a maximum overlap, would lead to emission levels between 53 and $55 \mathrm{GtCO}_{2} \mathrm{eq}$ by 2030, compared to a level of 54 to $56 \mathrm{GtCO}_{2}$ eq resulting from NDCs alone.
\end{abstract}

\section{Introduction}

International climate policy within the United Nations Framework Convention on Climate Change (UNFCCC) so-far has focused mostly on commitments from national governments. In the Paris Agreement (UNFCCC, 2015b), countries world-wide agreed to keeping the increase in global average temperature to well below $2{ }^{\circ} \mathrm{C}$ above pre-industrial levels and pursuing efforts to limit temperature increase to $1.5{ }^{\circ} \mathrm{C}$. As a first step towards this goal, countries have submitted Intended Nationally Determined Contributions (INDCs) in the run-up to the COP21 meeting in Paris, which after ratifying the Paris Agreement become NDCs. It has been shown that together, the NDCs are not expected to reduce greenhouse gas (GHG) emissions sufficiently towards a $2{ }^{\circ} \mathrm{C}$ emission pathway: the median emissions gap between GHG emission levels resulting from NDCs and the $2{ }^{\circ} \mathrm{C}$ limit by 2030 is estimated to be between 11 and $14 \mathrm{GtCO}_{2}$ eq (Rogelj et al., 2016).

The change towards more bottom-up action within the UNFCCC also included the acknowledgement of non-Party stakeholders as important parties in taking climate action (UNFCCC, 2015a). Non-Party stakeholders can be defined as any group participating in global (climate) governance that is not a sovereign state (Chan et al., 2016; Nasiritousi et al., 2016). They include non-state actors such as civil society, the private sector, financial institutions, cities and other subnational authorities. Note that the definition of non-state actors is often not made explicit in literature. Here, the categorisation of the NAZCA portal is used: "NAZCA brings together the commitments to action by companies, cities, subnational regions, investors and civil society" (UNFCCC, 2015a, 2015b), and thus include sub-national actors. Many take actions as a member of International Cooperative Initiatives (ICIs), that share a common goal and are mostly driven by likeminded countries (Widerberg and Pattberg, 2015). In addition, coalitions of the willing, which are groups of national governments, are also taking action on climate change outside the UNFCCC, often under the umbrella of other UN organisations. All these initiatives widen the scope of international climate policy by including new actors beside national governments (Hajer et al., 2015), and new coalitions outside the UNFCCC.

To clearly demarcate these new initiatives, we use Slingerland et al. (2011) that identified the above occurrences as "alternative routes that offer specific advantages in terms of increasing societal support for greenhouse gas (GHG) reductions". In this paper, we focus specifically

\footnotetext{
* Corresponding author.

E-mail address: Mark.Roelfsema@pbl.nl (M. Roelfsema).
} 
on transnational emission reduction initiatives (TERIs), which can be defined as international activities outside the UNFCCC driven by non-state actors or coalitions of national governments that have committed to reduce greenhouse gas emissions. TERIs often operate in specific sectors and/or together with specific actors. It was decided to focus on international activities in this paper (in contrast to national-scale initiatives) as these can be expected to lead to most reductions (UBA, 2016), thus complying to a pragmatic reason to restrain the analysis to a clearly defined list of measures and avoid too much overlap between them.

Clearly, it is important to assess the potential reduction potential of TERIs and their contribution beyond current NDCs. Previous studies have shown that the potential impact of TERIs can be large, but assessments also differ substantially. The differences are caused by selecting different climate initiatives or including different overlap assumptions or baseline assumptions. A first group of studies have addressed the mitigation potential of initiatives beyond national governments. According to Blok et al. (2012), 21 coherent major initiatives, already existing or proposed, together are estimated to reduce GHG emissions by $10 \mathrm{GtCO}_{2}$ eq by 2020 relative to a $56 \mathrm{GtCO}_{2} \mathrm{eq}$ business-as-usual level, assuming that a significant upscaling of existing initiatives is possible and that proposed initiatives will organise themselves. The New Climate Economy (2015) estimates that state- and nonstate actors would together achieve emission reductions of 16 to 26 $\mathrm{GtCO}_{2} \mathrm{eq}$ by 2030 relative to the business-as-usual level of $69 \mathrm{GtCO}_{2} \mathrm{eq}$, if they cooperate, scale up ambition and remove barriers. A second group of studies focused on existing commitments of initiatives only, based on current participation levels. Hsu et al. (2015) analysed 29 existing action statements with quantifiable targets, announced at the New York Climate Summit, and projected a total reduction of 2.5 $\mathrm{GtCO}_{2} \mathrm{eq}$ by 2020 , relative to the business-as-usual level of $59 \mathrm{GtCO}_{2} \mathrm{eq}$. UNEP (2015a) estimated that a wide selection of non-state climate initiatives with concrete mitigation actions and/or quantified mitigation targets would reduce emissions by $2.9 \mathrm{GtCO}_{2} \mathrm{eq}$, with a range of 2.5-3.3 $\mathrm{GtCO}_{2}$ eq by 2020 relative to the Current Policy Scenario of the World Energy Outlook 2014. UBA (2016) estimates that 19 initiatives, based on their quantifiable goal, are estimated to reduce between 5-11 $\mathrm{GtCO}_{2}$ eq annual reductions by 2030 compared to an NDC emission level of $53-56 \mathrm{GtCO}_{2} \mathrm{e}$.

This study uses the Integrated Assessment Model (IAM) IMAGE (Stehfest et al., 2014) to get an order estimate of the emission level after implementation of TERIs that existed at the time of COP21 in Paris, and the potential overlap with existing pledges and NDCs made by national governments in the context of the UNFCCC. We focus on a list of TERIs available just before the Paris Agreement, as more information is available on these measures allowing quantitative assessment. To our knowledge, this is the first study on the effectiveness of TERIs that uses an IAM framework. The advantage of doing so is that the analysis is based on a consistent emission scenario, including both energy-related and agriculture, forestry and land-use (AFOLU) emissions, which enables not only an estimate of the global impact of TERIs in terms of total reductions, but also the total emission level after implementation of TERIs. The IMAGE model represents a useful tool for analysis given the relatively detailed sectoral representation of this IAM compared to others. This study goes beyond existing studies on TERIs by assessing the impact of a selected set of large TERIs in a more consistent way, but also by paying more attention to the overlap with pledges/NDCs by discussing our results in the context of different existing methods. In order to assess the effectiveness of TERIs it is crucial to know how the TERIs overlap with government policies. So-far, this question has only been partly addressed by Hsu et al. (2015), UNEP (2015a) and UBA (2016). We use information on the TERIs to assess the maximum potential overlap, which should be regarded as a conservative approach.

It should be noted that TERIs often have other objective than direct emission reductions, such as networking and knowledge sharing (Chan et al., 2016; Michaelowa and Michaelowa, 2016), which were not included in our assessment. However, it is important to note that these are considered relevant for successful implementation (Widerberg and Pattberg, 2015) (see Section 5).

In addition, it should also be noted that analysing the reductions resulting from TERIs involves some important challenges. First, there is no GHG accounting framework in place yet for non-state action, and no global model exists that can assess climate policy of non-state actors. Second, individual actor emission estimates, targets and trends are not publicly or readily available. Third, no existing consistent framework is available yet that could assess TERI commitments. Given these limitations, our assessment should be regarded as a first attempt to quantify the effect of TERIs by connecting business-as-usual projections developed in the IMAGE model to aggregated actors and sectors. This paper can be seen as starting point for further analysis of new or expanded emission reduction initiatives.

\section{Methodology and data}

\subsection{Selection of TERIs}

The TERIs assessed in this study have been selected from the Climate Initiatives Platform (UNEP and Ecofys, 2015) and supplemented with potentially high-impact initiatives found in UN (2015), UNFCCC (2013, 2014), Wouters (2013). The aim was to select the largest initiatives that cover most economic sectors. Overlap between initiatives was kept small by selecting the largest initiative per sector. This selection should enable making a first-order estimate of the impact on GHG emissions that can be expected from climate action outside the UNFCCC.

Only those TERIs were selected i) that include multiple parties and act in multiple countries/regions (i.e. no bilateral initiatives were included), ii) that have a large expected global impact (roughly 0.1 $\mathrm{GtCO}_{2}$ eq or more), iii) that have clear commitments with quantified mitigation targets or concrete measures, or estimates are available based on GHG emissions from publications or literature iv) for which it is specified how the overall target (if any) is applied to individual actors, v) that only include direct GHG emission target or specific measures, e.g. no finance, subsidies and carbon taxes. The Supplementary material includes the full list of TERIs including our assessment on the above criteria. This material also includes a description of TERIs that were not selected, but have potential future impact if scaled up. The cut-off date for selection was 1 May 2015 (meaning that sufficient material was available to make an assessment of the impact). Clearly, in the future the list of TERIs included can be further expanded, but given the fact that this paper for the first time presents an assessment of TERIs in an IAM the focus here is mostly on presenting a first order estimate and showing how such analysis can be done.

\subsection{Implementation of TERIs in IMAGE}

While analysis of climate policies in models has often been done by implementing a generic carbon price to induce cost-effective policies in all sectors, here instead we try to implement reduction targets or measures as specifically formulated by the TERIs, in a similar manner as been done to asses country pledges and domestic climate policies by Roelfsema et al. (2014) and deep reduction measures by (Deetman et al., 2014). The first step was to identify the possible impact of TERIs on GHG emissions, based on the assumption that TERIs deliver on their commitments.

Ideally, the model would include sufficient detail to represent the commitments made by TERIs. At the same time, however, global IAM models often operate at a more aggregated scale in order to ensure transparency (see Section 5.1 for more discussion on this topic). This proves a challenge in representing the TERIs.

The IMAGE 3.0 model is a dynamic integrated assessment framework to analyse global change (Stehfest et al., 2014), and has the advantage that among the IAM models it is relatively detailed, making it 
Table 1

Global baseline emissions and emission reductions for individual international initiatives.

\begin{tabular}{|c|c|c|c|c|c|c|c|}
\hline & \multirow[t]{2}{*}{ Target year } & \multicolumn{3}{|c|}{ Baseline $\left(\mathrm{GtCO}_{2} \mathrm{eq}\right)$} & \multicolumn{2}{|c|}{ Reduction $\left(\mathrm{GtCO}_{2} \mathrm{eq}\right)$} & \multirow[t]{2}{*}{ Overlap with above initiatives } \\
\hline & & 2010 & 2020 & 2030 & 2020 & 2030 & \\
\hline \multicolumn{8}{|l|}{ Actor } \\
\hline Carbon Disclosure Project & 2020 & 3.2 & 3.8 & 4.2 & 0.7 & 0,8 & \\
\hline C40 Cities and Covenant of Mayors & $2020-2050$ & 3.5 & 4.6 & 5.3 & 0.6 & 0.7 & $25 \%$ \\
\hline \multicolumn{8}{|l|}{ Sector } \\
\hline Cement Sustainability Initiative & 2050 & 0.5 & 0.6 & 0.7 & 0.1 & 0.1 & $10 \%$ \\
\hline Global Fuel Economy Initiative & $2020 / 2050$ & 0.5 & 0.8 & 1.0 & 0.2 & 0.5 & $4 \%$ \\
\hline Kigali Amendment & 2043 & 0.5 & 1.0 & 1.3 & 0.0 & 0.7 & $0 \%$ \\
\hline Global Methane Initiative & 2022 & 4.1 & 5.1 & 5.9 & 0.5 & 1.2 & $0 \%$ \\
\hline New York Declaration of forests & $2020 / 2030$ & 1.0 & 0.5 & 0.4 & 0.3 & 0.7 & $0 \%$ \\
\hline International Maritime Organization & $2020 / 2050$ & 0.6 & 0.6 & 0.7 & 0.1 & 0.2 & $0 \%$ \\
\hline International Civil Aviation Organization & $2020 / 2050$ & 0.5 & 0.6 & 0.9 & 0.1 & 0.3 & $0 \%$ \\
\hline Zero Routine Flaring by 2030 & 2030 & 0.1 & 0.1 & 0.1 & 0.0 & 0.1 & $70 \%$ \\
\hline Overlap & & & & & 0.2 & 0.3 & \\
\hline Total & & & & & 2.5 & 5.0 & \\
\hline
\end{tabular}

suitable as a starting point for our work. The model consists of 26 world regions and the economic sectors energy supply, industry, transport, buildings, agriculture and land use. The model output comprises AFOLU GHG emissions from the IMAGE land-use model and energyrelated emissions from the energy-model TIMER. The main drivers of the baseline scenario are population and GDP, the projections of which are taken from the SSP2 scenario (SSP2 database, 2015).

The assessment consisted of four steps for each TERI, after which the total impact on the global level was determined

1. Determine aggregated 2010 GHG emissions, based on publications by the initiatives;

2. Determine TIMER/IMAGE baseline projections for emission growth, selecting specific sectors and accounting for overlap between actors;

3. Determine GHG emission reductions, and make simple assumptions for overlap between actors based on literature estimates and applying the overlap factors after construction of baselines;

4. Determine overlap with pledges/NDCS. The assumption is that there is full overlap if TERIs and pledges/NDCs apply to the same country and same actor.

Non-state actors are not modelled explicitly in the IMAGE model, and therefore, this assessment relies on literature estimates to derive globally aggregated targets or reduction estimates. Details on assumptions per TERI are found in the Supplementary material. As national policies are expected to be implemented to achieve NDCs, and to avoid complexity of overlap between national policies and non-state policies, we did not include national climate policies in the baseline (see Section 5).

The baseline emission projections for sector and actor initiatives were derived in two steps. This was done at an aggregated global level for actor initiatives (cities and companies) and on IMAGE region level for sector initiatives. First, a sector baseline trend was derived for the sectors in which TERIs have targeted emission reductions. For initiatives that act in multiple sectors, an emission baseline trend was constructed using the weighted average of the IMAGE sectoral trends, the weighting being based on the emission shares of the relevant sectors. A global companies baseline trend was constructed based on the global baseline emissions from the industry and service sectors (The Greenhouse Gas Protocol, 2012a); for the global cities baseline trend it was assumed that they act in the following sectors: urban buildings, passenger transport (excluding aviation), and small industry sectors (excluding cement and steel sector), including electricity supply for these sectors (The Greenhouse Gas Protocol, 2012b). Although $\mathrm{CH}_{4}$ emissions from waste are an important source, they were excluded because the aggregated emissions and targets as published by the initiatives were $\mathrm{CO}_{2}$ only. Second, a baseline for individual TERIs was constructed based on information about current emission levels as published by the TERIs and the emission trend as derived in step 1. If no information regarding current emission levels was available, the baseline was constructed by downscaling the IMAGE baseline based on the percentage of emissions in 2010 represented by participants (which was available). Overlap between individual cities was based on literature (see Section 3.1), and overlap between cities and companies was based on assuming full overlap of indirect (electricity) emissions (that represent $50 \%$ of total 2010 global city emissions) and assuming $50 \%$ of overlap in location (i.e. for those companies that are located in cities and both have reduction targets). The latter was assumed as no literature estimates were found. These overlaps were applied after the construction of the actor baselines.

Emission reduction targets for actor initiatives are mostly set on individual basis for cities and companies. We have aggregated these to global targets, based on literature or TERI publications, and applied them to the global IMAGE business-as-usual projection. In general, emission reduction targets from sector initiatives were applied to each IMAGE region and aggregated to the global level. For TERIs with targets before 2030, targets were extrapolated to 2030 on the assumption that an equivalent effort will be made, i.e. the same relative emission reduction compared to baseline until 2030 was assumed. Targets after 2030 were linearly interpolated (see Table 1 for actual target years). TERIs were assumed to overlap each other if they act in the same country and sector. As no individual non-state actor data was available, the level of overlap was calculated based on the fraction of total emissions from the overlapping sectors and regions in 2010 and applied to 2020 and 2030 reductions. More specifically for cities and companies, assumptions on overlap in reductions were the same as those assumed for the baseline development. Overlap between initiatives was calculated after global emission reduction for individual initiatives were calculated. The latter was done in a specific order (see Section 3) and was an arbitrary choice, but does not affect the total overlap between TERIs. Where possible and relevant, the calculation of the level of overlap was done at a regional level.

\subsection{Overlap with NDCs}

In addition to overlap between different TERIs, emission reductions from TERIs may overlap with reductions put forward by countries in the context of the UNFCCC. To show the additionality of the TERIs to pre2020 pledges and post-2020 NDCs, we have included a pledge/NDC scenario, based on the emission ranges from the UNEP (2014, 2015b) reports. To estimate the maximum potential overlap between TERIs and pledged reductions, it was assumed that TERIs do not lead to additional 
reductions in countries that submitted pledges or NDCs, provided that these occur in sectors that are included in the pledges and cover the same greenhouse gases. It is assumed that TERI targets that are more ambitious compared to pledges/NDCs will be compensated with less or downscaled ambition by other actors (see Section 5 ).

\section{Selected climate initiatives}

The long list of TERIs consisted of 184 climate initiatives from the Climate Initiatives Platform, and 13 were added from Wouters (2013), 7 from UNFCCC (2013), 5 from UNFCCC (2014) and 3 UN lead initiatives from UN (2015). From this long list, eleven were selected: seven international cooperative initiatives, three UN lead initiatives, and one private governance network (see Supplementary material).

\subsection{Description of individual international initiatives}

This section briefly describes the individual TERIs. In the long list of climate initiatives were no large international cooperative initiatives of companies that are expected to result in significant emission reductions (see Supplementary material for criteria). However, outside these initiatives many have committed themselves to GHG reduction targets, as reported by the Carbon Disclosure Project (CDP). The CDP is a transnational private governance network that engages in climate action in the business sector (Bulkeley and Newell, 2015). CDP encourages companies to set GHG emission reduction targets (CDP, 2014) and collects and captures data company commitments and emissions (which is not publicly available). The aggregated emission level of 70 of the world's largest publicly listed companies in 2014 was $3.4 \mathrm{GtCO}_{2} \mathrm{eq}$, $65 \%$ of which have set emission reduction targets (CDP, 2015a, 2015b). The latter group can be divided into $35 \%$ that have set targets in line with staying on track by 2030 to meet the global $2{ }^{\circ} \mathrm{C}$ goal, $15 \%$ that have set less ambitious targets, and $15 \%$ that have set targets which are not expected to lead to GHG emission reductions. The annual emission reduction rate for companies consistent with achieving the $2{ }^{\circ} \mathrm{C}$ goal is estimated at about 1.4\% (CDP, 2012; Moorhead and Nixon, 2014). As no information exists on the expected emission reduction for companies with less ambitious targets, we have simply assumed half of the annual emission reduction, so $0.7 \%$. These reduction rates were applied until 2030. The future baseline trend was based on the global IMAGE baseline trend for all business sectors, excluding China, as almost no companies in this country are participating in the CDP programme.

Two city initiatives were included in this analysis: 1) The C40 Cities initiative and 2) the Covenant of Mayors. The cities included in these initiatives are, based on our IMAGE baseline, responsible for approximately $25 \%$ of GHG emissions from all the world's cities in 2010. The C40 Cities is a network of 75 megacities representing 5\% of global GHG emissions (C40 Cities, 2014). The analysis of the C40 initiative is based on the C40 publication (2013), in which it is estimated that the 59 cities that were taking part at the time could achieve $11 \%$ reduction by 2020 relative to the baseline. These emissions were scaled to the population of the additional 16 cities that have joined since 2013 (C40 Cities, 2015). The Covenant of Mayors currently has more than 5700 signatories (Covenant of Mayors, 2015), representing 186 million people. The participating cities are expected to commit to meet and exceed the EU 20\% reduction target for 2020. Of all signatories, 3400 have composed Sustainable Energy Action Plans which have been analysed and accepted by the Covenant of Mayors. It constitutes a $28 \%$ overall GHG reduction target for 2020 relative to the base year, which is 1990 for $26 \%$ of the cities, 2000 for $12 \%$ and $2005-2008$ for $62 \%$ (Kona et al., 2015). The baseline trajectory was calculated by applying IMAGE baseline emission growth rates for GHG emissions to the 1990 and 2005-2008 emission levels and scaling the results to the population of the participating cities for which action plans have not yet been analysed and accepted. The overlap between the two city initiatives is assumed to be $25 \%$, based on Wouters (2013), and is applied both to baseline projections and emission reductions. The latter are equal to 0.1 $\mathrm{GtCO}_{2} \mathrm{eq}$.

The Cement Sustainability Initiative (CSI) has set company targets to reduce $\mathrm{CO}_{2}$ intensity in line with the Cement Technology Roadmap from IEA and WBCSD (2009). This initiative represents 24 companies accounting for $30 \%$ of global cement emissions (WBCSD, 2012). It aims at reducing $\mathrm{CO}_{2}$ emissions through four key technology options (IEA and WBCSD, 2009): 1) thermal and electric efficiency improvement, 2) alternative fuels in the cement kiln heating process, 3) producing cement with a lower clinker content, and 4) carbon capture and storage (CCS). The CSI technology roadmap includes global targets for 2050 and estimates for $\mathrm{CO}_{2}$ emission intensity reductions, defined as tonnes $\mathrm{CO}_{2}$ emissions per ton cement, resulting from these technologies up to 2050 (IEA and WBCSD, 2009). Until 2030, mainly the first three technology options are relevant and are estimated to reduce $\mathrm{CO}_{2}$ emission intensity by $25 \%$ relative to 2012 levels (IEA and WBCSD, 2009). This reduction is in line with the overall 2050 target of a $45 \%$ decrease in $\mathrm{CO}_{2}$ intensity relative to 2012 (IEA and WBCSD, 2009).

The Global Fuel Economy Initiative (GFEI) aims to reduce fuel consumption of new cars by $50 \%$ in 2030 compared to average 2005 levels and works together with government and partners to achieve this goal. This overall target is applied to all participating countries in the initiative. It also states a long-term goal for 2050, which consists of an average 50\% increase in fuel efficiency for all cars compared to 2005 . At the end of 2013, 20 countries participated in the GFEI, of which countries in Asia, Central and Eastern Europe, Latin America and Africa (GFEI, 2014). The emission reductions were projected by implementing the increased efficiency in the IMAGE transport model (Girod et al., 2012) for the model regions that include the 20 countries that are participating in the GFEI.

The Kigali Amendment to the Montreal Protocol, aims for a phase-down of HFC emissions with a delayed phase-down for developing countries (UNEP, 2016). Although mitigation of HFC emissions is dealt with in the UNFCCC negotiations, this has not led to substantial reductions up to now. With no impending global controls on HFCs, inclusion of HFCs under the Montreal Protocol would likely stimulate more stringent emission reductions (Velders et al., 2012). All countries participate in the Montreal Protocol, therefore to assess the impact of this protocol on GHG emissions relative to the business-as-usual pathway, all countries are expected to act according to the Amendment targets. The analysis of the impact of the HFC proposal on emissions accounts for the substitution of hydrochlorofluorocarbons (HCFCs) by HFCs, as was prescribed in the Amendment. The historic HCFCs emission levels are based on EPA (2013).

The objective of the Global Methane Initiative (GMI) is to mitigate climate change by advancing cost-effective near-term methane recovery from fossil-fuel production, transport, agriculture, agricultural waste, landfills, and wastewater. Currently 42 countries are member of the initiative, including large such as Brazil, China, European Union, India, and the United States. Although the GMI does not specify a final year, it published a fact sheet which included cost-effective reductions until 2020 (GMI, 2011). In our assessment, we made use of US-EPA cost curves (EPA, 2013) to identify cost-effective reductions per emission source for 2030. It was assumed that cost-effective reductions take place at US $\$ 15 / \mathrm{tCO}_{2} \mathrm{e}$, since this is considered a realistic cost level for all sources (GMI, 2011). The Climate and Clean Air Coalition (CCAC) also aims at reducing $\mathrm{CH} 4$ emissions. As the CCAC only specifies a reduction potential and has large overlap with GMI, this was not included in our analysis.

The New York Declaration of Forests (NYDF) aims at reducing emissions from deforestation and forest degradation (REDD) and has set quantified reduction targets. With the declaration, 26 national governments, 23 large multinationals and more than 50 civil society and indigenous organisations endorse a global timeline to halve natural forest loss by 2020, and strive to end it by 2030 (New York Declaration of Forests, 2014). In addition, the declaration calls for restoring 150 
million hectares of forests and croplands by 2020 and an additional 200 million hectares by 2030 (New York Declaration of Forests, 2014). The participants in the NYDF represented $20 \%$ of global $\mathrm{CO}_{2}$ deforestation emissions in 2010. It was assumed that ending forest loss implies zero emissions from biomass burning. The impact of reforestation and restoration was assessed on the basis of IMAGE regrowth dynamics, which determine the carbon uptake until 2020 and 2030, given the staged restoration of 350 million hectares of land in the initiative.

The International Maritime Organization (IMO) adopted mandatory measures to improve energy efficiency and to reduce GHG emissions from international shipping. These measures have entered into force on 1 January 2013 and address the largest and most energyintensive ship types responsible for about $70 \%$ of GHG emissions from international shipping (IMO, 2011). As almost all countries in the world are participating in the IMO, it was assumed they all implement the mandatory measures. The projected reductions were derived by applying the reduction percentages from the IMO study to the IMAGE baseline. The range depends on the degree of implementation of costeffective activities and baseline fleet growth assumptions as described in IMO (2011).

In 2010, the International Civil Aviation Organization (ICAO) adopted a resolution in which reference was made to commitments announced by the International Air Transport Association (IATA) and other sectoral organisations on behalf of the international air transport industry. These commitments are to improve $\mathrm{CO}_{2}$ efficiency by an average of $1.5 \%$ per year from 2009 until 2020 and a long-term goal of reducing carbon emissions by $50 \%$ by 2050 compared to 2005 levels (ICAO, 2010). The latter was translated into a global fuel efficiency improvement rate of $2 \%$ per year from 2021 to 2050 , based on the basis of volume of fuel used per revenue kilometre performed (IATA, 2009b). Emission reductions for international aviation have been excluded from the commitments made within the UNFCCC as it appeared difficult to allocate emissions to specific countries. The participants in the ICAO that are expected to take measures, represent $50 \%$ of global international aviation emissions. IATA estimates a reduction of $21 \%$ in $\mathrm{CO}_{2}$ emissions from international aviation due to the expected fleet renewal compared to a scenario without fleet renewal with 2020 emissions of about $0.9 \mathrm{GtCO}_{2} \mathrm{eq}$ (IATA, 2009a, 2009b).

The Zero Routine Flaring by 2030 initiative was introduced by the Word Bank and brings together oil companies, national governments and development institutions to agree on eliminating $\mathrm{CO}_{2}$ emissions from gas flaring by 2030 (World Bank, 2015). Currently 10 governments endorsed the principle of the initiative.

\section{Results of TERI assessment on global GHG emissions}

\subsection{Impacts of the TERIS}

The selected initiatives cover almost all energy and AFOLU sectors, except for the freight transport and rural residential sector (see Supplementary material). Table 1 shows the estimated emission reductions of the various TERIs. The largest absolute reductions are expected from company, city, the NYDF, the Kigali Amendment, and the Global Methane Initiative (see Table 1). Except for the HFC proposal, these TERIs represent a large part of global emissions in 2010. Together, these initiatives with the largest impact are projected to decrease emissions by $4.1 \mathrm{GtCO}_{2}$ eq by 2030 . The initiatives with the largest relative reductions include NYDF, the Kigali Amendment, and the Global Fuel Initiative - all of which are expected to have reductions of $50 \%$ or more by 2030 relative to baseline.

The CDP companies are projected to reduce $0.7 \mathrm{GtCO}_{2} \mathrm{eq}$ GHG emissions from a baseline level of $3.8 \mathrm{GtCO}_{2}$ eq by 2020 , which is extrapolated to $0.8 \mathrm{GtCO}_{2} \mathrm{eq}$ reductions relative to a baseline level of 4.2 $\mathrm{GtCO}_{2}$ eq for 2030. The city initiatives cover the C40 Cities initiative and the Covenant of Mayors initiative. The reductions for the C40 initiative are projected at respectively $0.4 \mathrm{GtCO}_{2} \mathrm{eq}$ emissions from a baseline level of $3.5 \mathrm{GtCO}_{2} \mathrm{eq}$ by 2020 and $0.5 \mathrm{GtCO}_{2} \mathrm{eq}$ emissions from a level of $4.1 \mathrm{GtCO}_{2} \mathrm{eq}$ by 2030 . For the Covenant of Mayors, the projected reductions are $0.3 \mathrm{MtCO}_{2} \mathrm{eq}$ by 2020 from a baseline level of 1.4 $\mathrm{GtCO}_{2}$ eq and $0.3 \mathrm{GtCO}_{2}$ eq by 2030 from a level of $1.7 \mathrm{GtCO}_{2}$ eq. The overlap between the two TERIs is projected to be approximately 0.2 $\mathrm{GtCO}_{2}$ eq by 2020 and 2030. All countries participating in the Kigali Amendment are projected to reduce GHG emissions by $0.7 \mathrm{GtCO}_{2} \mathrm{eq}$ from a baseline level of $1.3 \mathrm{GtCO}_{2} \mathrm{eq}$, and even more reductions are expected after 2030, as the proposal runs until 2043.The baseline emissions for the New York Declaration of Forests from deforestation are already projected to decrease from $1.0 \mathrm{GtCO}_{2} \mathrm{eq}$ in 2010 to 0.4 $\mathrm{GtCO}_{2}$ eq in 2030 for the countries that participate in this initiative. On top of that, the emission reduction from the NYDF is estimated at 0.7 $\mathrm{GtCO}_{2}$ in 2030 , of which $0.5 \mathrm{GtCO}_{2}$ is the result of ending natural forest loss, and $0.2 \mathrm{GtCO}_{2}$ is the result of reforestation and restoration. The Global Methane Initiative largely overlaps with the Climate and Clean Air coalition, and the latter is therefore not analysed, but could also reduce emissions from the non-Kyoto gases black carbon and organic carbon. See Table 1 for all results.

In the IMAGE implementation, the total projected reductions of all TERIs add up to $2.5 \mathrm{GtCO}_{2}$ eq by 2020 and $5.0 \mathrm{GtCO}_{2}$ eq by 2030 , leading to projected emission levels of $51.2 \mathrm{GtCO}_{2} \mathrm{eq}$ by 2020 and 56.1 $\mathrm{GtCO}_{2}$ eq by 2030 (see Fig. 1). It is assumed that all selected TERI targets are fully achieved. This number includes an assessment of the overlap between TERIs, as some TERIs act in the same countries and sectors. The overlap between TERIs, however, is expected to be

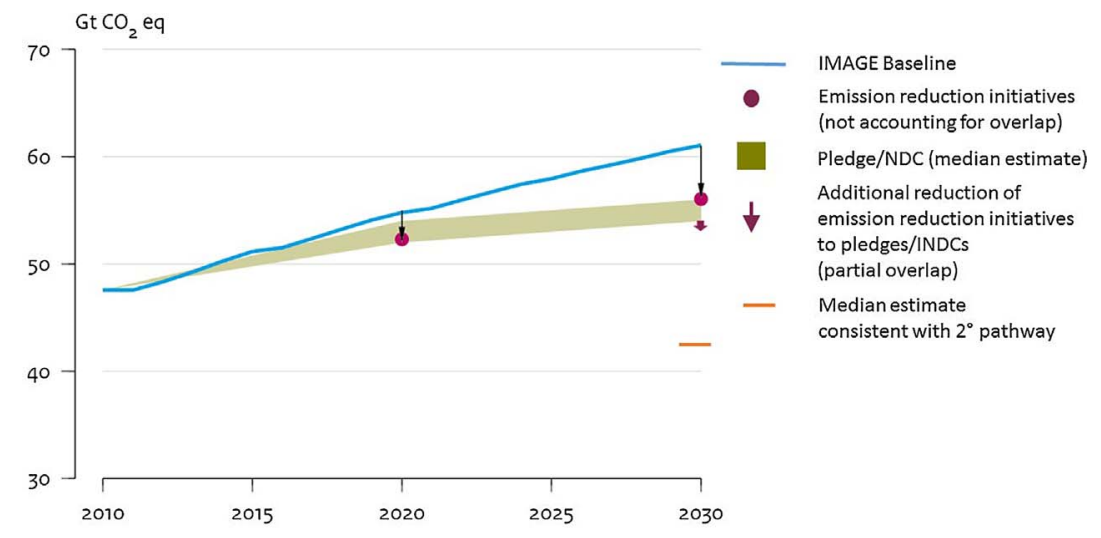

Fig. 1. GHG emission levels after implementation of transnational emission reduction initiatives; The red dot represents reductions not considering overlap with pledges/NDCs, and the red arrow represents additional reductions to pledges/NDCs when overlap is taken into account. These emission levels are compared with the pledge/NDC scenario and median estimate consistent with $2{ }^{\circ} \mathrm{C}$ pathway, based on the UNEP Gap reports from 2014 (pre-2020 pledges) and 2015 (post2020 NDCs). (For interpretation of the references to colour in this figure legend, the reader is referred to the web version of this article.)

Source: PBL; UNEP 2014 
relatively small; approximately $0.2 \mathrm{GtCO}_{2}$ eq by 2020 and $0.3 \mathrm{GtCO}_{2} \mathrm{eq}$ by 2030 (see Table 1), not including the overlap between the two city initiatives. Note that overlap for cities was calculated at two stages: 1) overlap between city initiatives and 2) overlap between cities and companies, both at the global level using the fraction of emissions that are emitted in the same region (excluding China for companies) and sector.

\subsection{Comparison of the TERIs and the impact of the pledges and NDCs}

Earlier assessments have shown that the 2020 pledges of national governments are projected to lead to (median) global emission levels between $52 \mathrm{GtCO}_{2}$ eq and $54 \mathrm{GtCO}_{2}$ eq by 2020 (UNEP, 2014) and 2030 NDCs to a (median) level between $54 \mathrm{GtCO}_{2} \mathrm{eq}$ and $56 \mathrm{GtCO}_{2}$ eq by 2030 (UNEP, 2015b). The global reductions of the selected TERIs, if they are fully achieved, could be of a similar order of magnitude as the global reductions as pledged by the Parties under the umbrella of the UNFCCC (Fig. 1). But, this estimate does not consider possible overlap between TERIs and pledges/NDCs. Overlap was calculated by making the conservative assumption, that full overlap exists between TERIs and the pledges/NDCs, if they target the same Kyoto gases in the same countries and sectors (see Section 5). The part that does not overlap, can be considered as additional GHG reduction to pledges/NDCs.

Obviously, the TERIs targeting the international shipping and aviation sectors are additional to pledges/NDCs (see Fig. 2). The Global Methane Initiative and the HFC amendment to the Montreal protocol

Top-500 companies in the Carbon Disclosure Project Cement Sustainability Initiative

Cities initiatives

Global Fuel Economy Initiative

HFCs proposal to the Montreal Protocol

Global Methane Initiative

New York Declaration on Forests

International Maritime Organization

International Civil Aviation Organization Zero Routine Flaring by 2030

Total of initiatives

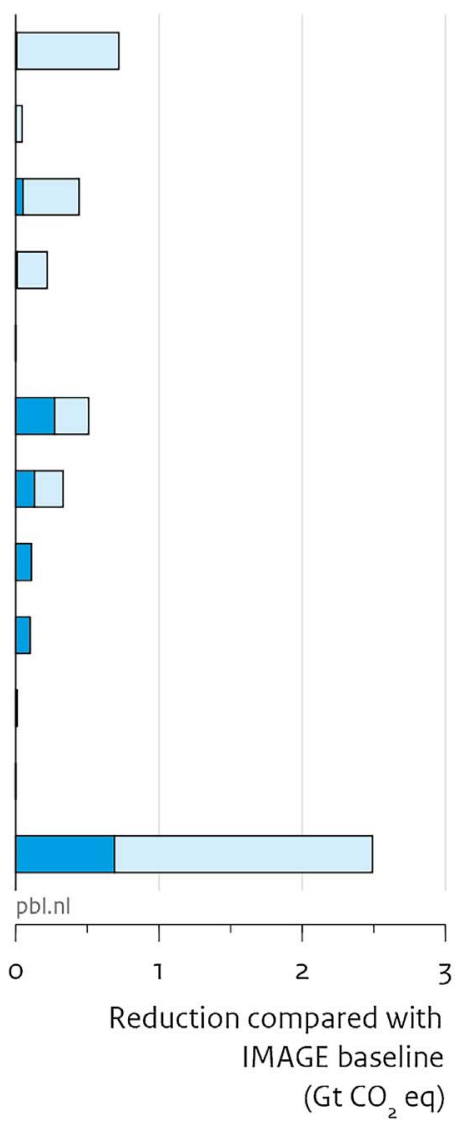

Additional emission reductions initiatives, on top of pledges/INDCs

Overlap between initiatives and pledges/INDCs Source: PBL also have relatively low overlap as these TERIs partly act in countries without pledges or in sectors that are not included in pledges made by specific countries (i.e. non- $\mathrm{CO}_{2}$ gases for China and India). Overall, the overlap could amount to $70 \%-80 \%$, equal to $1.8 \mathrm{GtCO}_{2}$ eq by 2020 and $3.9 \mathrm{GtCO}_{2} \mathrm{eq}$ by 2030 (see Fig. 2). Therefore, a conservative projection is that the additional reductions relative to the pledge/NDC scenario is $0.7 \mathrm{GtCO}_{2}$ eq by 2020 and $1.2 \mathrm{GtCO}_{2}$ eq by 2030 (see Fig. 1). Note that overlap between TERIs, representing overlap in membership or in sector (see Table 1), was applied before calculating overlap between pledges/NDCs and TERIs.

Assuming a maximum overlap, the combined effect of pledges/ NDCs and TERIs leads to a projected emission level of 51-53 $\mathrm{GtCO}_{2} \mathrm{eq}$ by 2020 and to $53-55 \mathrm{GtCO}_{2}$ eq by 2030 (see Fig. 1). The median emission level in 2030 to stay on track to meet the $2{ }^{\circ} \mathrm{C}$ goal, based on cost-effective implementation of climate policy from 2020 onwards, is $42 \mathrm{GtCO}_{2}$ eq (UNEP, 2015b). Due to the large potential overlap, the combined effect is only slightly larger than the effect of pledges/NDCs alone, and therefore TERIs contribute only slightly to reducing the gap with emission levels necessary to stay on track to meet the $2{ }^{\circ} \mathrm{C}$ goal (see Fig. 1).

A comparison of our study with those of (UNEP, 2015a) and (Hsu et al., 2015) shows that the studies included different TERIs in their analysis, but that many of the TERIs aim to reduce emissions in the same sectors. For instance, the Global Methane Initiative included in our study aims at reducing methane emissions from, among others, agriculture and oil \& gas systems, which are treated as separate

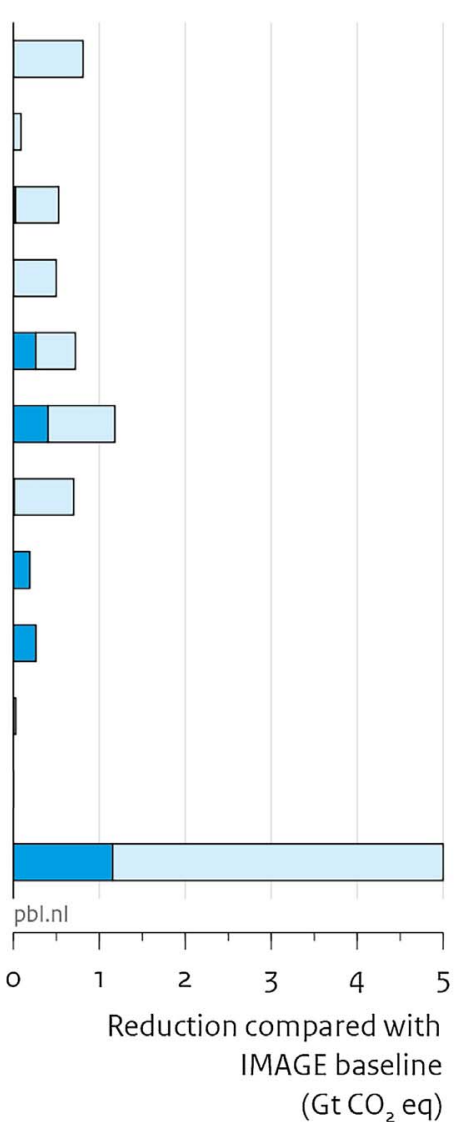

Reductions resulting from the initiatives have been corrected for overlap

Fig. 2. Additional emission reductions in 2020 and 2030 from international cooperative initiatives to pledge/NDC scenario from UNEP Gap reports from 2014 and 2015. 
initiatives in the UNEP (2015a) study. The comparison also shows that the definition of TERIs differs between the studies. This study includes international climate action outside the UNFCCC, while UNEP considers initiatives initiated by non-state actors only. Hsu et al. (2015) only takes into account initiatives that submitted action plans to the New York Climate Summit that was held in 2014. Despite these differences, it can be concluded that the different studies arrive at total reductions by 2020 which are in the same order of magnitude. UBA (2016) estimates much larger additional reductions to NDCs by 2030, which is, among others, caused by different assumptions on overlap with pledges and NDCs, as will be discussed in Section 5.1.

\subsection{Assumptions on overlap between TERIs and pledges/NDCs}

Our assessment showed that the potential for overlap with pledges and INCDs is large, as TERIs often target the same countries and sectors that are covered by pledges/NDCs. (UNEP, 2015a) concluded that the overlap is much lower (about a third) than the $70 \%-80 \%$ of potential overlap we have found. The most significant difference in estimating the potential overlap between our methodology and the method of UNEP is that the latter included domestic policies that could result in achieving pledge/NDC targets, and assumed no overlap between TERIs and reductions achieved from domestic climate policies already in place. In other words, UNEP assumed that all TERIs lead to reductions additional to existing domestic policies. The question is, whether this is really the case. It would not be difficult to think of a domestic climate policy which leads to achievement of the same goals set in an TERI. Therefore, these reductions will also help to achieve the targets set by the two city initiatives included in our assessment. In addition, the UBA (2016) study assesses the impact of non-state actors compared to NDCs, assuming both non-state targets and NDC targets are reached. It is not fully clear how they assess overlap, especially whether reductions in one specific sector or for one specific greenhouse gas are compared to NDC reductions that apply economy-wide. It is also relevant whether additional reductions are determined in absolute or relative terms compared to NDC targets. If the latter is assumed, this implicitly assumes that all non-state actors without GHG emission reduction commitments will reduce emissions in line with NDCs, which may not be the case. Moreover, not having a reduction commitment could indicate that these non-state actors have no climate policy in place and therefore might be more inclined to follow a business-as-usual pathway. Our study implicitly assumes that non-state actors without climate policy at least will not offset the commitments made by other non-state actors. But it does make the conservative estimate, that only additional reductions occur in those sectors and countries that are not covered by NDCs.

More in-depth assessments of overlaps on country level are necessary to determine if non-state action will be additional to NDCs. This should include explicit assumptions on climate policy by non-state actors without commitments. In addition, including domestic climate policies would enable assessment beyond NDC reduction commitments and therefore could provide better insight into the interaction and projected overlap between national governments and non-state actors (at sector level), which is important for further research.

\section{Discussion and conclusion}

One of the expectations of TERIs is that they can realise additional emission reductions beyond those proposed by national governments under the UNFCCC (Blok et al., 2012), but Widerberg and Pattberg (2015) raise the question whether this is really the case. In order to assess this, we have selected those TERIs that have set quantified emission- or energy reduction targets. However, the purpose of TERIs in climate policy implementation is broader then bringing mere additional reduction to pledges and NDCs. For example, Michaelowa and Michaelowa (2017) assess four criteria necessary, but not sufficient, for effective mitigation. They show that about half of the initiatives do not meet any of the criteria, giving rise to the conclusion that other objectives play a role. This is confirmed by Chan et al. (2016), showing that most quantitative targets did not relate directly to GHG emission reductions by initiatives launched at the UN Climate Summit in 2014. But, these initiatives are shown to link organisations (domestic and international) beyond those that participate in TERIs, thereby presenting the possibility of diffusion of policy and learning (Cao and Ward, 2017). In addition, national policies and transnational governance could mutually reinforce each other (Roger et al., 2017), increasing effectiveness, certainty of implementation and accelerating implementation. Thus, many initiatives that were not included in our assessment, seem less focused on a singular outcome, resulting in more experimental forms of climate governance, but could create important opportunities and have the ability to effectively respond to climate change (Hoffmann, 2011). Moreover, as many of the initiatives are still small at this moment, they could have significant potential to scale up. Some TERIs with potential to scale up are listed in the Supplementary material.

Assessing the impact and effectiveness of TERIs and measuring progress in terms of absolute emission reductions is a challenge, among others caused by the lack of common baselines and multiple measures to record emission reductions (Bulkeley and Newell, 2015). This also holds for potential future impact. Therefore, the analysis of this paper should be regarded as a first attempt to assess the impact of climate action outside the UNFCCC, using an integrated assessment model. No global models are available (yet) that account for non-state actor climate policy, and data on individual non-state actors is not publicly and readily available. Together with the calculation of overlap, these are important challenges for the research community.

\subsection{Limitations of integrated assessment models}

Although IAMs are very suitable to assess the impact of TERIs on a global level and for large emitting countries, they have limitations with regard to modelling all details of non-state actions. Most IAMs only represent large countries and aggregate others to regions. Therefore, reduction commitments of smaller countries need to be aggregated. The IMAGE model has the advantage that approximately $65 \%$ of global GHG emissions by 2010 represent individual large countries.

Policy instruments, such as feed-in-tariffs, are in general not well represented in IAMs, making it difficult to explicitly model interactions between national governments and none-state actors. Actor-based models would be better able to translate the mental models of policymakers with respect to the assumed behavior of important economic actors into quantitative numerical simulation models including the response of actors to the proposed policies (Hasselman et al., 2015), but most of these models focus on relatively small regions or only cover parts of the energy system (De Cian et al., 2017).

In addition, actors are not explicitly modelled in IAMs. However, GHG commitments from different actors can be aggregated at country level (outside the model), if national GHG inventories and those of nonstate actors can be linked on sector level. This is under the condition that commitments, especially for companies, can be broken down to country and sector level. If Monitoring, Reporting, Verification (MRV) of non-state action is improved, more information will be available, which could improve the representation of TERIs in the IMAGE model.

\subsection{Sensitivity analysis}

For the largest individual TERI calculations we have conducted a sensitivity analysis on the most important assumptions. For the CDP initiative, we have analysed the effect of $20 \%$ lower/higher annual reductions, which would change total GHG emissions by 2030 by \pm 35 $\mathrm{MtCO}_{2}$ eq. For the $\mathrm{C} 40$ initiative we have scaled baseline emissions on the basis of population to include the newly joined 16 cities. This could 
be improved by using other drivers, such as population density or heating degree days of urban areas (Singh and Kennedy, 2015). If we assume that the scaling factor is $\pm 10 \%$ lower or higher, the emission level after implementation of city targets would be approximately 0.35 $\mathrm{GtCO}_{2}$ eq lower or higher. For the Global Methane Initiative, we have assessed the sensitivity of the carbon price ( $\$ 10$ or $\$ 30$ instead of $\$ 15$ ), and found that the reduction relative to baseline changes by \pm 100 $\mathrm{MtCO}_{2}$ eq by 2030. For the NY Declaration of forests calculations, sensitivity was not assessed, because only the assumption on scaling to GHG emissions was a possible candidate, but no applicable FAOSTAT (2017) data was available.

\subsection{Uncertainty of selection and progress made by TERIs}

One of the main assumptions for selecting the TERIs was that they cover the most important sectors. After the Paris Agreement, especially many international cooperative initiatives seem to have emerged or progressed. If they include more individual actors or pledge higher ambitions, our estimate of impact on GHG emissions could change. Therefore, our estimate is a first step, taking into account some of the largest initiatives, but the analysis could be extended and improved.

It is difficult to assess whether TERIs will deliver what they have promised, as the commitments that are put forward are voluntary and often aspirational. MRV is a possible instrument to enforce accountability and compliance, but now this is mostly lacking for TERIs (IVM, 2015). Data gaps especially exist around emerging and developing economies in many northern-led initiatives. To some degree this is also true for national policies, although MRV is already much more advanced here. Currently some TERIs have started publishing databases with information on progress of cities and companies, such as the CDP Open Data Portal (CDP, 2015a) and the Carbon Climate Registry (ICLEI, 2015). For example, the Carbon Action Initiative, a CDP initiative, found that $80 \%$ of the companies correctly reported all details necessary to accurately assess the achievability and ambition of reduction targets. For other initiatives, we have not found any such databases. The NAZCA UNFCCC database could fill this gap in the future.

Climate action by TERIs could increase fragmented action and this assessment did not account for positive and negative spillover (leakage) effects. The impact of carbon leakage on frontrunner countries in the energy sector is estimated to be below $16 \%$ of additional emission reductions to the currently implemented national policies and does not provide a strong counter-argument against adoption of more stringent mitigation action by pioneering regions (Arroyo-Currás et al., 2015), and therefore possibly also not to pioneering TERIs. This estimate is within the range of most ex ante modelling studies that conclude to leakage rates in the range of 5-20\% (Branger and Quirion, 2013).

Despite these uncertainties, our analysis gives a valid (first attempt) order of magnitude estimate of committed TERI impact on global GHG reductions, based on a consistent set of sectoral baseline emission projections.

\subsection{Conclusion}

TERIs can be an important to international climate policy as they could ensure and accelerate implementation of mitigation measures, but also add additional reductions to international pledges/NDCs made by national governments. These TERIs have formulated a wide set of measures that could reduce emissions. In some cases, these measures are additional to those formulated by governments in the UNFCCC framework, but often there is an overlap.

The selected set of large TERIs are projected to deliver annual emission reductions of $2.5 \mathrm{GtCO}_{2} \mathrm{eq}$ by 2020 from a no-policy baseline emission level of $53.7 \mathrm{GtCO}_{2} \mathrm{eq}$ and $5.0 \mathrm{GtCO}_{2} \mathrm{eq}$ by 2030 from a nopolicy baseline emission level of $61.1 \mathrm{GtCO}_{2} \mathrm{eq}$, provided that they are fully achieved. The largest reductions are expected from company, city, NYDF, and the Kigali amendment to the Montreal Protocol and the
Global Methane Initiative. Together, these largest TERIs are projected to decrease emissions by $3.9 \mathrm{GtCO}_{2}$ eq by 2030 . Overlap between all selected TERIs is estimated to be small. At a global level, the projected emission levels achieved by implementation of measures put forward by TERIs are roughly similar to what may be expected based on pledges and NDCs for 2020 and 2030.

Our conservative assessment is that the potential overlap in reductions between the TERIs assessed and pledges/NDCs is large and could amount to $70 \%$ by 2020 and $80 \%$ by 2030 . This is a maximum estimate, based on the assumption that emission reductions from TERIs will not lead to additional reductions where these occur in those countries that made pledges and NDCs, provided that they occur in sectors included in such pledges/NDCs. In order to exactly determine the degree of overlap an exact and detailed analysis of all measures taken needs to be made. Given that is not possible at the moment, transparent assumptions are needed.

The combined effect of TERIs and pledges/NDCs, assuming the maximum overlap of 70-80\%, would lead to emission levels of between 53 and 55 GtCO2eq by 2030, compared to an emission range based on the impact of NDCs alone of 54 to 56 GtCO2eq (UNEP, 2015b). Although insufficient to close the emission gap between pledges/NDCs and the emission level necessary to remain on track to stay below the $2{ }^{\circ} \mathrm{C}$ limit, it could bring us closer to meeting this goal.

Setting up and improving Monitoring, Reporting and Verification is an important pre-condition for showing TERI progress and assess effectiveness of implementation. This would also be an important precondition to improve integration and assessment of TERIs into Integrated Assessment Models such as the IMAGE model.

This research resulted in important lessons learned for future impact assessments. Aggregation of non-state actors emissions and targets is necessary for Integrated Assessment Models, and for this they need to be more publicly and readily available. In addition, overlap between emissions and targets of non-state actors and national governments then needs to be accounted for, but policy interaction at more instrumental level would be difficult.

\section{Appendix A. Supplementary data}

Supplementary data associated with this article can be found, in the online version, at https://doi.org/10.1016/j.gloenvcha.2017.11.001.

\section{References}

Arroyo-Currás, T., Bauer, N., Kriegler, E., Schwanitz, V.J., Luderer, G., Aboumahboub, T., Giannousakis, A., Hilaire, J., 2015. Carbon leakage in a fragmented climate regime: the dynamic response of global energy markets. Technol. Forecast. Soc. Change 90, 192-203.

Blok, K., Höhne, N., van der Leun, K., Harrison, N., 2012. Bridging the greenhouse-gas emissions gap. Nat. Clim. Change 2, 471-474.

Branger, F., Quirion, P., 2013. Climate Policy and the 'carbon haven' effect. WIREs Clim. Change 5, 53-71.

Bulkeley, H., Newell, P., 2015. Governing climate change. Routledge, Taylor \& Francis Group.

C40 Cities, 2013. The Rio Numbers: C40 Cities can Reduce Greenhouse Gas Emissions by over a Billion Tons Per Year in 2030. C40 Cities. http://c40-production-images.s3. amazonaws.com/researches/images/17_C40_The_20Rio_20Numbers_20-_20City_ 20Emissions_20Reduction_20Potential.original.pdf?1388095836.

C40 Cities, 2014. C40 City Diplomacy Update. http://iet.jrc.ec.europa.eu/ energyefficiency/sites/energyefficiency/files/files/documents/events/slidesfragola. pdf.

C40 Cities, 2015. C40 Blog. C40 Cities. http://www.c40.org/blog_posts/10-years-ofresults-c40-by-the-numbers.

CDP, 2012. Business Resilience in an Uncertain, Resource-constrained World. CDP Global 500 Climate Change Report 2012. Carbon Disclosure Project (CDP). https://www. pwc.com/my/en/assets/services/cdp-global-500-report-2012.pdf.

CDP, 2014. Climate Action and Profitability. CDP S\&P 500 Climate Change Report 2014. Carbon Disclosure Prjoject (CDP), North America. https://b8f65cb373b1b7b15febc70d8ead6ced550b4d987d7c03fcdd1d.ssl.cf3.rackcdn.com/cms/reports/ documents/000/000/845/original/CDP-SP500-leaders-report-2014.pdf? 1472032950.

CDP, 2015a. CDP Open Data Portal. https://data.cdp.net/.

CDP, 2015b. Mind the Science. Science Based Targets. Carbon Disclosure Project (CDP). 
http://sciencebasedtargets.org/mindthescience/MindTheScience.pdf.

Cao, X., Ward, H., 2017. Transnational climate governance networks and domestic regulatory action. Int. Interact. 43, 76-102.

Chan, S., Falkner, R., Goldberg, M., van Asselt, H., 2016. Effective and geographically balanced? An output-based assessment of non-state climate actions. Clim. Policy $1-12$.

Climate Summit, 2014. New York Declaration on Forests, Action Statement and Action Plan. New York. http://www.un.org/climatechange/summit/wp-content/uploads sites/2/2014/07/New-York-Declaration-on-Forests 1-Dec-2015.pdf.

Covenant of Mayors, 2015. Signatories. http://www.covenantofmayors.eu/about/about/ signatories_en.html? commitments $2=1 \&$ commitments $3=1 \&$ commitments $1=1$.

De Cian, E., Dasgupta, S., Hof, A.F., Van Sluisveld, M.A.E., Köhler, J., Pfluger, B., Van Vuuren, D.P., 2017. Actors, Decision-making, and Institutions in Quantitative System Modelling. Fondazione Eni Enricco Mattei, Venice. http://www.feem.it/en/ publications/feem-working-papers-note-di-lavoro-series/actors-decision-makingand-institutions-in-quantitative-system-modelling/.

Deetman, S., Hof, A.F., van Vuuren, D.P., 2014. Deep $\mathrm{CO}_{2}$ emission reductions in a global bottom-up model approach. Clim. Policy 15, 253-271.

EPA, 2013. Global Mitigation of Non- $\mathrm{CO}_{2}$ Greenhouse Gases: 2010-2030. United States Environmental Protection Agency (EPA), Washington DC (report EPA-430-R-13-011). https://www.epa.gov/global-mitigation-non-co2-greenhouse-gases.

FAOSTAT, 2017. Food and Agriculture Data. http://faostat3.fao.org/home/E.

GFEI, 2014. Fuel Economy, State of the World 2014. The World Is Shifting into Gear on Fuel Economy. Global Fuel Economy Initiative (GFEI), FIA Foundation, International Energy Agency (IEA), International Transport Forum, UNEP, International Council on Clean Transportation (ICCT). http://www.fiafoundation.org/media/44120/gfeiannual-report-2014-executive-summary.pdf.

GMI, 2011. Global Methane Emissions and Mitigation Opportunities. Global Methane Initiative (GMI). https://www.globalmethane.org/documents/analysis_fs_en.pdf.

Girod, B., van Vuuren, D.P., Deetman, S., 2012. Global travel within the $2{ }^{\circ} \mathrm{C}$ climate target. Energy Policy 45, 152-166.

Hajer, M., Nilsson, M., Raworth, K., Bakker, P., Berkhout, F., de Boer, Y., Rockström, J., Ludwig, K., Kok, M., 2015. Beyond cockpit-ism: four insights to enhance the transformative potential of the sustainable development goals. Sustainability 7 , 1651-1660.

Hasselman, K., Cremedes, R., Filatova, T., Hewitt, R., Jaeger, C., Kovalesvsky, D., Voinov, A. Winder, N., 2015. Free-riders to forerunners. Nat. Geosci. 8, 895-898.

Hoffmann, M.J., 2011. Climate Governance at the Crossroads Experminenting with a Global Response After Kyoto. Oxford University Press.

Hsu, A., Moffat, A.S., Weinfurter, A.J., Schwartz, J.D., 2015. Towards a new climate diplomacy. Nat. Clim. Change 5, 501-503.

IATA, 2009a. Aviation and Climate Change Pathway to Carbon-neutral Growth in 2020. International Aviation Transport Association (IATA). https://www.iata.org/ whatwedo/environment/Documents/aviation-climatechange-pathway-to2020.pdf.

IATA, 2009b. The IATA Technology Roadmap Report. 3rd edition. International Aviation Transport Association (IATA). https://www.escholar.manchester.ac.uk/uk-ac-manscw:106699. http://www.iata.org/publications/Pages/technology-roadmap.aspx.

ICAO, 2010. Environmental Report 2010. International Civil Aviation Organization. http://www.icao.int/environmental-protection/Documents/Publications/ENV_ Report_2010.pdf.

ICLEI, 2015. Carbonn Climate Registry. http://carbonn.org/.

IEA, WBCSD, 2009. Cement Technology Roadmap 2009. Carbon Emission Reductions up to 2050. World Business Council on Sustainable Development (WBCSD), International Energy Agency (IEA). https://www.iea.org/publications/ freepublications/publication/Cement.pdf.

IMO, 2011. Assessmnet of IMO Mandated Energy Efficiency Measures for International Shipping. International Maritime Organization (IMO). http://www.imo.org/en/ MediaCentre/HotTopics/GHG/Pages/default.aspx.

IVM, 2015. In: Widerberg, O., Pattberg, P. (Eds.), Non-state Actors in a Paris Agreement. Are Cities and Companies Bridging the Ambition Gap? Institute for Environmental Studies (IVM), FORES.

Kona, A., Melica, G., Calvete, S.R., Zancancell, P., Iancu, A., Gabrielaitiene, I., Saheb, Y., Janssens-Manhout, G., Bertoldi, P., 2015. The Covenant of Mayors in Figures and Performance Indicators: 6-year Assessment. Joint Research Centre (JRC).

Michaelowa, K., Michaelowa, A., 2016. Transnational climate governance initiatives: designed for effective climate change mitigation? Int. Interact. 1-27.

Michaelowa, K., Michaelowa, A., 2017. Transnational climate governance initiatives: designed for effective climate change mitigation? Int. Interact. 43, 129-155.

Moorhead, J., Nixon, T., 2014. Global 500 Greenhouse Gases Performance 2010-2013: 2014 Report on Trends, A Thomson Reuters Financial and Risk White Paper. BSD Consulting, Thomson Reuters.

Nasiritousi, N., Hjerpe, M., Linnér, B.-O., 2016. The roles of non-state actors in climate change governance: understanding agency through governance profiles. International Environmental Agreements: Politics, Law and Economics 16, 109-126.

Roelfsema, M., den Elzen, M.G.J., Höhne, N., Hof, A.F., Braun, N., Fekete, H., Brandsma, R., Larkin, J., Böttcher, H., 2014. Are major economies on track to achieve their pledges for 2020? An assessment of domestic climate and energy policies. Energy Policy 67, 781-796.

Rogelj, J., den Elzen, M., Hohne, N., Fransen, T., Fekete, H., Winkler, H., Schaeffer, R., Sha, F., Riahi, K., Meinshausen, M., 2016. Paris agreement climate proposals need a boost to keep warming well below 2 degrees C. Nature 534, 631-639.

Roger, C., Hale, T., Andonova, L., 2017. The comparative politics of transnational climate governance. Int. Interact. 43, 1-25.

SSP2 database, 2015. SSP Database (Shared Socioeconomic Pathways) - Version 1.0. https://secure.iiasa.ac.at/web-apps/ene/SspDb.IIASA.

Singh, S., Kennedy, C., 2015. Estimating future energy use and CO(2) emissions of the world's cities. Environ. Pollut. 203, 271-278.

Slingerland, S., Meyer, L., Van Vuuren, D.P., Den Elzen, M., 2011. Forks in the Road. Alternative Routes for International Climate Policies and Their Implications for the Netherlands. Netherlands Environmental Assessment Agency (PBL), Bilthoven.

Stehfest, E., Van Vuuren, D.P., Bouwman, L., Kram, T., Alkemade, R., Bakkenens, M., Biemans, H., Bouwman, A., Den Elzen, M., Janse, J., Lucas, P., Van Minnen, J., Müller, C., Prins, A., 2014. Integrated Assessment of Global Environmental Change with Model Description and Policy Applications IMAGE 3.0. PBL Netherlands Environmental Assessment Agency, Bilthoven.

The Greenhouse Gas Protocol, 2012a. A Corporate Accounting and Reporting Standard. . http://www.ghgprotocol.org/standards/corporate-standard.

The Greenhouse Gas Protocol, 2012b. Global protocol for community-Scale greenhouse gas emission inventories. An Accounting and Reporting Standard for Cities.

The New Climate Economy, 2015. Estimates of Emissions Reduction Potential for the 2015 Report: Technical Note, Seizing the Global Opportunity: Partnerships for Better Growth and a Better Climate. The New Climate Economy. http://2015. newclimateeconomy.report/misc/working-papers/.

UBA, 2016. In: Bundesamt, U. (Ed.), International Climate Initiatives - A Way Forward to Close the Emissions Gap? Initiatives' Potential and Role Under the Paris Agreement.

UN, 2015. Review of Activities and Resources Devoted to Address Climate Change in the United Nations System Organizations. Joint Inspection Unit, United Nations. https:// www.unjiu.org/en/reports-notes/JIU\%20Products/JIU_REP_2015_5_English.pdf.

UNEP, Ecofys, 2015. Climate Initiatives Platform. http://climateinitiativesplatform.org.

UNEP, 2014. The Emissions Gap Report 2014: A UNEP Synthesis Report. United Nations Environment Programme (UNEP), Nairobi.

UNEP, 2015a. Climate Commitments of Subnational Actors: A Quantitative Assessment of Their Emission Reduction Impact. United Nations Environment Programme (UNEP), Nairobi.

UNEP, 2015b. The Emissions Gap Report 2015: A UNEP Synthesis Report. United Nations Environment Programme (UNEP), Nairobi.

UNEP, 2016. The Kigali Amendment to the Montreal Protocol: HFC Phase-down - Ozon Action Fact Sheet. http://www.unep.fr/ozonaction/information/mmcfiles/7897-eOzonAction_Kigali_fS_quick_links.pdf. http://multimedia.3m.com/mws/media/ 13659240/unep-fact-sheet-kigali-amendment-to-mp.pdf.

UNFCCC, 2013. Compilation of information on mitigation benefits of actions, initiatives and options to enhance mitigation ambition. United Nations Framework Convention on Climate Change.

UNFCCC, 2014. Updated Compilation of Information on Mitigation Benefits of Actions, Initiatives and Options to Enhance Mitigation Ambition, Technical Paper, FCCC/TP/ 2014/3. www.unfccc.int.

UNFCCC, 2015a. Adoption Of The Paris Agreement, Proposal by the President, Draft Decision - /CP.21. UNFCCC, Paris. http://unfccc.int/resource/docs/2015/cop21/ eng/109.pdf.

UNFCCC, 2015b. Paris agreement, decision 1/CP.17. In: United Nations Framework Climate Change Convention. Paris.

Velders, G.J., Ravishankara, A.R., Miller, M.K., Molina, M.J., Alcamo, J., Daniel, J.S., Fahey, D.W., Montzka, S.A., Reimann, S., 2012. Climate change: preserving montreal protocol climate benefits by limiting HFCs. Science 335, 922-923.

WBCSD, 2012. The Cement Sustainability Initiative - 10 Years of Progress - Moving on to the Next Decade Geneva, Switerzland.

Widerberg, O., Pattberg, P., 2015. International cooperative initiatives in global climate governance: raising the ambition level or delegitimizing the UNFCCC? Global Policy 6, 45-56.

World Bank, 2015. Zero Routine Flaring 2030.

Wouters, K., 2013. Wedging the Gap. An Analysis of the Impact of Existing Large-scale Bottom-up Initiatives for Greenhouse Gas Emission Mitigation in 2020, Master Thesis. Ecofys, Universiteit van Utrecht. http://dspace.library.uu.nl/handle/1874/287883. 